\title{
Prophylactic glycopyrrolate reduces hypotensive responses in elderly patients during spinal anesthesia: a randomized controlled trial
}

\section{Le glycopyrrolate en prophylaxie réduit les épisodes d'hypotension induits par la rachianesthésie chez les patients âgés: une étude randomisée contrôlée}

\author{
Jinyoung Hwang, MD, PhD • Seongwon Min, MD, PhD • Chongsoo Kim, MD, PhD • \\ Namsu Gil, MD $\cdot$ Eunkyoung Kim, MD $\cdot$ Jin Huh, MD, PhD
}

Received: 20 March 2013/Accepted: 18 October 2013/Published online: 18 December 2013

(C) Canadian Anesthesiologists' Society 2013

\begin{abstract}
Background Hypotension during spinal anesthesia is a serious complication in elderly patients. We evaluated the effect of glycopyrrolate on hypotensive responses in elderly patients undergoing spinal anesthesia.

Methods Sixty-six patients older than $60 \mathrm{yr}$ of age scheduled for elective surgery with spinal anesthesia were included in the study. They received either glycopyrrolate $0.2 \mathrm{mg}$ (group G) or normal saline (group C) intramuscularly $15 \mathrm{~min}$ before spinal anesthesia. The following outcomes were evaluated after the induction of spinal anesthesia: the incidence of hypotension and bradycardia, the ephedrine requirement, mean arterial pressure, heart rate, and the incidence of nausea and vomiting.
\end{abstract}

Author contributions Jinyoung Hwang, Seongwon Min, Chongsoo Kim, and Jin Huh helped design the study and analyse the data. Jinyoung Hwang, Namsu Gil, Eunkyoung Kim, and Jin Huh helped conduct the study. Jinyoung Hwang and Jin Huh helped write the manuscript. Jinyoung Hwang, Seongwon Min, Chongsoo Kim, Namsu Gil, Eunkyoung Kim, and Jin Huh have seen the original study data and reviewed the analysis of the data. Jinyoung Hwang is the author responsible for archiving the study files.

J. Hwang, MD, PhD · S. Min, MD, PhD - C. Kim, MD, PhD .

N. Gil, MD - J. Huh, MD, PhD ( $₫)$

Department of Anesthesiology and Pain Medicine, SMG-SNU

Boramae Medical Center, Boramae-ro, Dongjak-gu,

Seoul 156-707, Republic of Korea

e-mail: amandla@empas.com; amandla@snu.ac.kr

E. Kim, MD

Department of Anesthesiology \& Pain Medicine, Seoul National

University Hospital, Seoul, Republic of Korea
Results Twenty-three of $33(70.0 \%)$ patients in group $C$ experienced hypotension compared with nine of 33 (27.3\%) patients in group $G$ (difference $=42.7 \%$; $95 \%$ confidence interval [CI]: 18.4 to 60.2; $P=0.001)$. The median [interquartile range] amount of ephedrine required was 5 [0-15] $\mathrm{mg}$ in group C compared with 0 [0-5] $\mathrm{mg}$ in group $G$ (difference $=5.0 \mathrm{mg} ; 95 \% \mathrm{CI}: 2.7$ to $7.3 ; \mathrm{P}=0.001$ ). Nine $(27.3 \%)$ patients in group $C$ experienced nausea and vomiting compared with 2 (6.1\%) in group $G$ (difference $=21.2 \%$; 95\% CI: 3.0 to 38.7; $P=0.044$ ). Three $(9.1 \%)$ patients in group $C$ experienced bradycardia compared with $1(3.0 \%)$ patient in group $G$ (difference $=6.1 \%$; 95\% CI: -7.6 to $20.8 ; P=0.613$ ).

Conclusion Prophylactic intramuscular glycopyrrolate reduced the occurrence and severity of hypotensive responses, the requirement for ephedrine, and the incidence of nausea and vomiting in elderly patients undergoing spinal anesthesia. The trial was registered at the Clinical Research Information Service, Republic of Korea (KCT0000556).

\footnotetext{
Résumé

Contexte L'hypotension survenant à la suite d'une rachianesthésie est une complication grave chez les patients âgés. Nous avons évalué l'effet du glycopyrrolate sur les épisodes d'hypotension induits par la rachianesthésie chez les patients âgés.

Méthode Soixante-six patients de plus de 60 ans subissant une chirurgie non urgente avec rachianesthésie ont participé à l'étude. Ils ont reçu soit $0,2 \mathrm{mg}$ de glycopyrrolate (groupe G), soit un sérum physiologique (groupe C) par voie intramusculaire 15 min avant la
} 
rachianesthésie. Après l'induction de la rachianesthésie, l'incidence d'hypotension et de bradycardie, les besoins en éphédrine, la tension artérielle moyenne, la fréquence cardiaque et l'incidence de nausées et vomissements ont été évalués.

Résultats Vingt-trois des 33 (70,0\%) patients du groupe Cont souffert d'hypotension, comparativement à neufdes 33 $(27,3 \%)$ patients du groupe $G$ (différence $=42,7 \%$, intervalle de confiance [IC] $95 \%: 18,4 \%$ à 60,2 \%, $P=0,001)$. La quantité moyenne (écart interquartile) d'éphédrine nécessaire était de 5(0-15) mg dans le groupe $C$ par rapport à 0 (0-5) $\mathrm{mg}$ dans le groupe $G$ (différence = 5,0 mg, IC $95 \%: 2,7$ à 7,3 mg, $P=0,001$ ). Neuf $(27,3 \%)$ patients du groupe Cont souffert de nausées et vomissements, comparativement à $2(6,1 \%)$ patients $d u$ groupe $G$ (différence $=21,2 \%$, IC $95 \%: 3,0 \%$ à $38,7 \%$, $P=0,044)$. Trois $(9,1 \%)$ patients du groupe C ont souffert de bradycardie, comparativement à $1(3,0 \%)$ patient $d u$ groupe $G$ (différence $=6,1 \%$, IC $95 \%:-7,6 \%$ à 20,8\%, $P=0,613$ ).

Conclusion Le glycopyrrolate administré par voie intramusculaire en prophylaxie a réduit la survenue et la gravité des épisodes d'hypotension, les besoins en éphédrine et l'incidence de nausées et vomissements après une rachianesthésie chez les patients âgés. Cette étude a été enregistrée au Service de renseignements pour la recherche (Research Information Service), République de Corée, no. KCT0000556.

Hypotension is one of the most frequent complications during spinal anesthesia. It results from the sympathetic blockade after induction of spinal anesthesia which sequentially decreases systemic vascular resistance and cardiac output. ${ }^{1}$ It is more common in elderly patients, with a reported incidence of $65-75 \%$. $^{2-4}$ In addition, hypotension during spinal anesthesia may be combined with bradycardia-caused by the blockade of sympathetic cardiac accelerator fibers that arise at T1-T4-to prevent the development of reflex tachycardia. ${ }^{5}$ Hemodynamic changes induced by spinal anesthesia can be deleterious in elderly patients with decreased cardiovascular reserve and other comorbidities due to the risk of organ ischemia. ${ }^{6}$

Several strategies, including intravenous fluid administration $^{7}$ and vasopressors, ${ }^{8}$ have been considered to prevent the occurrence of hypotension after the induction of spinal anesthesia. Nevertheless, prehydration in elderly patients is not always effective, ${ }^{2,9}$ and sometimes it may be risky in patients with cardiac and pulmonary dysfunction. Moreover, the use of prophylactic vasopressors is not always effective to prevent hypotension during spinal anesthesia and could cause excessive hypertension and tachycardia. ${ }^{2,10}$
Prophylactic glycopyrrolate, an anticholinergic, is expected to attenuate hemodynamic changes during spinal anesthesia; however, the effect of glycopyrrolate on hemodynamic changes in elderly patients undergoing spinal anesthesia is unclear. We hypothesized that prophylactic glycopyrrolate would reduce the incidence of hypotension, the requirement for ephedrine, and the incidence of bradycardia and nausea and vomiting during spinal anesthesia. In addition, we evaluated the effect of prophylactic intramuscular glycopyrrolate on hypotensive responses in elderly patients undergoing spinal anesthesia.

\section{Methods}

This study was approved in June 2012 by the Ethics Committee of SMG-SNU Boramae Medical Center, a metropolitan hospital serviced by Seoul National University Hospital. All patients provided written informed consent.

Patients older than $60 \mathrm{yr}$ of age and scheduled for elective surgery with spinal anesthesia were eligible for the study. Patients were excluded if they had cardiovascular, hepatic, pulmonary, or renal dysfunction, glaucoma, thyroid disease, prostatic hypertrophy, coagulopathy, or neuromuscular disease. Patients were also excluded if bleeding in excess of $100 \mathrm{~mL}$ was expected within the first hour following spinal anesthesia. Patient screening and enrolment were conducted by a nonparticipating anesthesiologist.

Patients were allocated to the control group (group C) or to the glycopyrrolate group (group G). An investigator not clinically involved in our study created the randomization sequence using a computer-generated random-number chart (Random Allocation Software Version 1.0-Isfahan University of Medical Sciences, Isfahan, Iran) with a block size of four and a 1:1 allocation ratio. The same investigator prepared sequentially numbered, opaque and sealed envelopes to implement the sequence. When each patient was transferred to the operating room, another investigator, also not clinically involved in the study, determined the treatment allocation by opening the envelope in the sequence. This same investigator then prepared the study drug, either glycopyrrolate $0.2 \mathrm{mg}$ $(1 \mathrm{~mL})$ or normal saline $(1 \mathrm{~mL})$ and provided the study drug to the anesthesiologists, also not involved in the study. The study drugs were prepared to be identical in appearance. All patients and care providers, including anesthesiologists, nurses, and study personnel, were kept blinded to the group allocation.

Premedication was not given to the patients. Routine monitoring, including electrocardiography, noninvasive arterial pressure, and pulse oximetry, was performed. The study drug was administered intramuscularly $15 \mathrm{~min}$ before 
the induction of spinal anesthesia. Glycopyrrolate was administered intramuscularly with the intention of avoiding abrupt tachycardia and gradually counteracting the hypotensive responses during spinal anesthesia. The timing for dispensing the glycopyrrolate was based on the patient's heart rate response following intramuscular injection. ${ }^{11}$ Group $\mathrm{C}$ received normal saline $(1 \mathrm{~mL})$ intramuscularly at the same time point. For a fluid preload, Ringer's solution $10 \mathrm{~mL} \cdot \mathrm{kg}^{-1}$ was administered intravenously over $15 \mathrm{~min}$. With the patient in the lateral position, a dural puncture was performed at the L 3-4 or $\mathrm{L}$ 4-5 intervertebral space using a 25-G Quinke needle, and hyperbaric bupivacaine (Bupivacaine $\mathrm{HCl}$ Injection $0.5 \%$ Hana $^{\circledR}$, Hana Pharm Co., Ltd., Korea) 14 mg with fentanyl $20 \mu \mathrm{g}$ was administered intrathecally. The arterial pressure and heart rate (HR) were monitored every minute for the first $20 \mathrm{~min}$ and then every five minutes until $60 \mathrm{~min}$. The height of the spinal block was assessed using loss of cold sensation with an alcohol swab five minutes and $20 \mathrm{~min}$ after the induction of spinal anesthesia.

Hypotension was defined as systolic arterial pressure less than $90 \mathrm{mmHg}$ or a decrease in mean arterial pressure (MAP) greater than $20 \%$ from the baseline value. In patients who met either criterion, ephedrine $5-10 \mathrm{mg}$ was administered intravenously until the arterial pressure increased above the threshold value. When the patient required $>40 \mathrm{mg}$ of ephedrine, phenylephrine was administered intravenously as a rescue drug. If bradycardia occurred (heart rate $<40$ beats $\cdot \mathrm{min}^{-1}$ ) without hypotension, atropine $0.5 \mathrm{mg}$ iv was given. Fluid management was left to the anesthesiologists' discretion. The following data were recorded on standardized data sheets: MAP, HR, the requirement for ephedrine, time to the first use of ephedrine, height of spinal block at five minutes and $20 \mathrm{~min}$ after induction of spinal anesthesia, the incidence of nausea and vomiting, the presence of dry mouth, the amount of fluid required, and the volume of blood loss during the first 60 min after induction of spinal anesthesia.

The primary outcome was the incidence of hypotension. The secondary outcomes included the use of ephedrine, the time to the first use of ephedrine, and the incidence of bradycardia and nausea and vomiting. A power analysis was performed based on a previous study where the incidence of hypotension in elderly patients during spinal anesthesia was approximately $70 \%{ }^{3}$ Considering that a clinically significant reduction in the incidence of hypotension was $35 \%$ in absolute terms, ${ }^{3} 31$ patients per group were required with an error of 0.05 (one-sided) and power of $80 \%$. To compensate for a $10 \%$ dropout rate, 34 patients were required for each group. Categorical data are summarized by frequency (percent), and continuous data are expressed by mean (SD) or by median [interquartile range] if the data were asymmetrically distributed. Point and interval estimates were determined for between-group differences. Statistical analysis was performed using the SPSS $^{\circledR} 12.0$ software (SPSS Inc., Chicago, IL, USA). The ephedrine requirements and the time to the first use of ephedrine were compared using the Mann-Whitney U test. Fisher's exact test was used to analyze the incidences of hypotension, bradycardia, and nausea and vomiting and the use of ephedrine. Between-group hemodynamic variables over time were analyzed using repeated measures analysis of variance (ANOVA). Between-group differences over time were assessed by introducing a group $\times$ time interaction term. A $P$ value of $<0.05$ was considered statistically significant.

\section{Results}

Seventy-two patients were recruited from July to November 2012, and four patients declined involvement in our study. Sixty-eight patients were randomized, and two patients were eliminated due to a failed spinal anesthesia; consequently, 66 patients were analyzed (Fig. 1). Patient characteristics, height of spinal block at five minutes and $20 \mathrm{~min}$, anesthetic time, fluid requirements, and estimated blood loss during the study period are presented in Table 1.

Twenty-three of $33(70.0 \%)$ patients in group C experienced hypotension compared with nine of 33 $(27.3 \%)$ patients in group $\mathrm{G}$ (difference $=42.7 \%$; $95 \%$ confidence interval $[\mathrm{CI}]: 18.4$ to $60.2 ; P=0.001)$. The number needed to treat to prevent one case of hypotension was 2.3 (95\% CI: 1.6 to 4.8 ), and the relative risk reduction (\%) was 61 (95\% CI: 29 to 79). The time to the first use of ephedrine was similar in both groups, but the amount of ephedrine required by patients in group $\mathrm{G}$ was less than that required by patients in group $\mathrm{C}$. The incidence of nausea and vomiting was higher in group $\mathrm{C}$ than in group $\mathrm{G}$; however, the incidence of bradycardia was similar between groups (Table 2).

Mean arterial pressure and HR over time are presented in Fig. 2. Repeated measures ANOVA revealed no significant between-group differences over time in MAP and HR.

Two patients in group $\mathrm{C}$ received phenylephrine to increase arterial pressure because their ephedrine requirements exceeded $40 \mathrm{mg}$.

\section{Discussion}

Regional anesthesia is often preferred to general anesthesia due to reduced pulmonary complications ${ }^{12}$ and protection against thromboembolic events. ${ }^{13}$ Nevertheless, elderly 


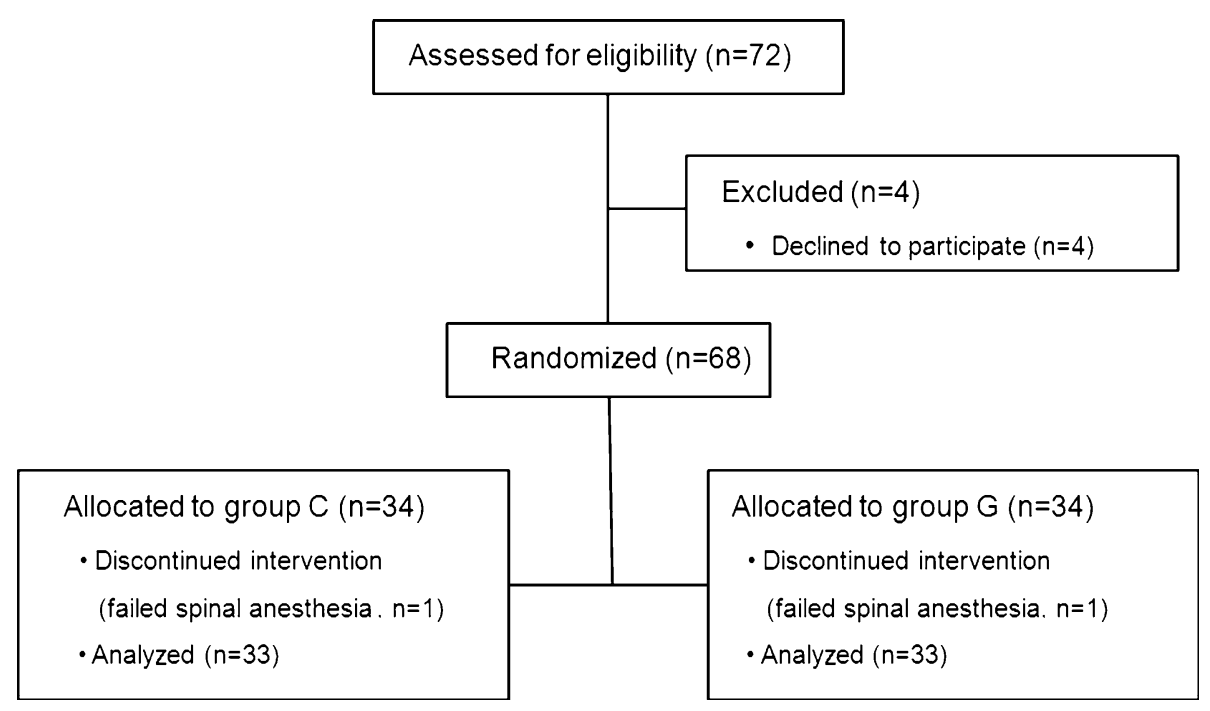

Fig. 1 Flow diagram. Seventy-two patients were assessed for eligibility and four patients were excluded. Sixty-eight patients were randomized and two patients (one patient from each group) were eliminated due to failed spinal anesthesia. Group $\mathrm{C}=$ control group; Group $\mathrm{G}=$ glycopyrrolate group

patients undergoing spinal anesthesia are highly susceptible to profound hypotension, which could cause detrimental complications such as organ ischemia. ${ }^{1,4,14}$ Both prevention and prompt treatment of spinal anesthesiainduced hypotension are important, but considering its frequency in elderly patients, prevention should be the rational approach. The present study showed that prophylactic intramuscular glycopyrrolate attenuated hypotensive responses in elderly patients undergoing spinal anesthesia and reduced the incidence of nausea and vomiting.

Glycopyrrolate is a quaternary amine with antimuscarinic effects. ${ }^{15}$ In contrast to atropine, a tertiary amine, glycopyrrolate does not cross the blood-brain barrier and cannot affect the central nervous system. ${ }^{16}$ Moreover, its chronotropic effect is much less than that of atropine. ${ }^{15} \mathrm{In}$ anesthetic practice, glycopyrrolate has been commonly used to reverse nondepolarizing muscle relaxants ${ }^{17,18}$ or to reduce oral secretions. ${ }^{19}$ Considering that hypotension induced by spinal anesthesia is related to sympathetic blockade accompanied by bradycardia, administration of glycopyrrolate could affect hemodynamic changes during spinal anesthesia. A few studies have evaluated the effect of glycopyrrolate on hypotension following induction of spinal anesthesia for Cesarean delivery, ${ }^{20-22}$ but the results were controversial. In addition, there is a lack of studies evaluating the effect of glycopyrrolate on hypotensive responses in elderly patients during spinal anesthesia.

In the current study, we found that prophylactic intramuscular glycopyrrolate significantly reduced the incidence of hypotension during spinal anesthesia when compared with the control group. These results are partly in agreement with some previous studies. Ure et al. ${ }^{23}$ showed that prophylactic glycopyrrolate administered intravenously during spinal anesthesia for Cesarean delivery reduced the ephedrine requirements by more than $50 \%$, although the incidence of hypotension was unaffected. In their study, the primary outcome was the incidence and severity of nausea, and nausea was thus managed first with fluids and ephedrine, which could blunt the recorded incidence of hypotension. In the study by Rucklidge et $a l^{20}$ on prevention of hypotension in parturients following subarachnoid block, the effects from pretreatment with glycopyrrolate were similar to the effects from pretreatment with ephedrine. Conversely, Yentis et al. ${ }^{21}$ reported that glycopyrrolate did not attenuate the severity of hypotension or the requirements for ephedrine in obstetric patients undergoing spinal anesthesia. Immediately after induction of spinal anesthesia, all patients were injected with prophylactic ephedrine $6 \mathrm{mg} i v$ in addition to glycopyrrolate or saline, which might have confounded the hemodynamic responses following spinal anesthesia.

Monitoring the severity of hypotension is also important in the maintenance of stable hemodynamics during spinal anesthesia. In our study, once hypotension occurred after induction of spinal anesthesia, the time to the first use of ephedrine was similar between the two groups. Nevertheless, patients receiving glycopyrrolate required significantly less ephedrine than patients in the control group, which was beneficial in the maintenance of stable hemodynamics, particularly in elderly patients.

Glycopyrrolate has a chronotropic effect through its antimuscarinic activity. ${ }^{15}$ When administered to patients 
Table 1 Patient characteristics

\begin{tabular}{|c|c|c|}
\hline & Group C $(n=33)$ & Group G $(n=33)$ \\
\hline Age (yr) & $69[64-74]$ & $70[66-74]$ \\
\hline $\operatorname{Sex}(M / F)$ & $7 / 26$ & $7 / 26$ \\
\hline Weight (kg) & $58.5[57.0-69.5]$ & $60.0[56.8-65.9]$ \\
\hline Height $(\mathrm{cm})$ & $153.9[150.0-158.5]$ & $155.2[151.3-160.0]$ \\
\hline ASA physical status I/II & $3 / 30$ & $4 / 29$ \\
\hline \multicolumn{3}{|l|}{ Spinal block height } \\
\hline \multicolumn{3}{|l|}{$5 \mathrm{~min}$} \\
\hline $\mathrm{T} 2$ & 2 & 1 \\
\hline T3 & 4 & 3 \\
\hline $\mathrm{T} 4$ & 7 & 5 \\
\hline T5 & 1 & 1 \\
\hline T6 & 9 & 14 \\
\hline $\mathrm{T} 7$ & 2 & 1 \\
\hline T8 & 5 & 6 \\
\hline T9 & 0 & 0 \\
\hline $\mathrm{T} 10$ & 3 & 2 \\
\hline \multicolumn{3}{|l|}{$20 \mathrm{~min}$} \\
\hline T2 & 5 & 4 \\
\hline T3 & 6 & 5 \\
\hline $\mathrm{T} 4$ & 15 & 15 \\
\hline T5 & 1 & 4 \\
\hline T6 & 6 & 4 \\
\hline $\mathrm{T} 7$ & 0 & 0 \\
\hline T8 & 0 & 1 \\
\hline T9 & 0 & 0 \\
\hline $\mathrm{T} 10$ & 0 & 0 \\
\hline Anesthetic time (min) & 130 [115-135] & 120 [103-130] \\
\hline Fluid requirement (mL) & 130 [100-200] & $120[100-150]$ \\
\hline Estimated blood loss (mL) & $30[20-30]$ & $20[20-30]$ \\
\hline \multicolumn{3}{|l|}{ Type of operation } \\
\hline Surgery for hip fracture & 16 & 18 \\
\hline Total hip arthroplasty & 10 & 7 \\
\hline Repair for inguinal hernia & 7 & 8 \\
\hline
\end{tabular}

Values shown are median [interquartile range] or patient numbers ASA = American Society of Anesthesiologists; Group C = control group; Group $\mathrm{G}=$ glycopyrrolate group; $\mathrm{MAP}=$ mean arterial pressure; $\mathrm{HR}=$ heart rate; $\mathrm{T}=$ thoracic. Fluid requirement and estimated blood loss were assessed during the first hour after the induction of spinal anesthesia

undergoing spinal anesthesia, it can prevent bradycardia but increase heart rate. In Chamchad et al.'s study, ${ }^{22}$ prophylactic intravenous glycopyrrolate prevented bradycardia after spinal anesthesia, but patients receiving glycopyrrolate showed a significantly higher heart rate than patients in the placebo group. Yentis et al. ${ }^{21}$ also reported that patients pretreated with intravenous glycopyrrolate showed a greater increase in heart rate compared with the control group. When glycopyrrolate is administered intravenously, heart rate increases within one minute. ${ }^{11}$ This abrupt tachycardia could be serious in elderly patients, particularly patients with cardiovascular disease. ${ }^{24}$ On the other hand, the use of an intramuscular injection of glycopyrrolate can be an alternative approach to prevent the occurrence of abrupt tachycardia and can gradually counteract the hypotensive responses following spinal anesthesia. According to a previous study ${ }^{25}$ showing the pharmacokinetics of intramuscular glycopyrrolate $\left(8 \mu \mathrm{g} \cdot \mathrm{kg}^{-1}\right)$, rapid absorption was found, with a mean peak plasma concentration after $16.1 \mathrm{~min}$ and a mean elimination half-life of $75.4 \mathrm{~min}$. A significant heart rate occurred in $15 \mathrm{~min}$, lasting up to $60 \mathrm{~min}$. In the present study, glycopyrrolate was administered intramuscularly $15 \mathrm{~min}$ before the induction of spinal anesthesia based on the heart rate response following intramuscular injection. ${ }^{11,18}$ As a result, clinically significant tachycardia was not observed in patients receiving glycopyrrolate. Additionally, no significant difference was observed in the recorded incidence of bradycardia between the two groups. Bradycardia might have been underestimated because it was defined as HR of $<40$ beats $\min ^{-1}$ rather than $<50$ or 60 beats $\min ^{-1}, 22,26$ and hypotension was treated first with ephedrine.

It should be emphasized that patients with cardiovascular disease were excluded from our study due to concerns about the chronotropic effect of glycopyrrolate. Further studies are required to evaluate the effectiveness and safety of intramuscular glycopyrrolate in patients with cardiovascular disease. Additionally, ephedrine is commonly used to treat hypotension following spinal anesthesia, and when administered intramuscularly, its onset time and duration of action is similar to that of intramuscular glycopyrrolate. The onset of action after intramuscular administration is ten to $20 \mathrm{~min}$, and the duration of pressor and cardiac responses to ephedrine is one hour after intramuscular administration of $25-50 \mathrm{mg}$. ${ }^{\text {A }}$ Thus, further evaluation of the effects of intramuscular glycopyrrolate and ephedrine on hypotension in the elderly following spinal anesthesia would also be helpful for clinical practice.

Nausea and vomiting is an uncomfortable complication following spinal anesthesia. We found that prophylactic glycopyrrolate reduced the incidence of nausea and vomiting in accordance with a previous study. ${ }^{23}$ As glycopyrrolate does not cross the blood-brain barrier, ${ }^{16}$ it might not affect the cholinergic pathways at the central nervous system. Nevertheless, nausea and vomiting is usually accompanied by hypotensive responses through organ hypoperfusion, and thus it could be reduced by preventing the occurrence of hypotension.

\footnotetext{
$\overline{\text { A Data sheet }}$ of product characteristics 2012, New Zealand; Hospira NZ Limited.
} 
Table 2 Adverse effects and the use of ephedrine after spinal anesthesia

\begin{tabular}{|c|c|c|c|c|}
\hline & $\begin{array}{l}\text { Group C } \\
(n=33)\end{array}$ & $\begin{array}{l}\text { Group G } \\
(n=33)\end{array}$ & $\begin{array}{l}\text { Between-group } \\
\text { difference }\end{array}$ & $P$ value \\
\hline Hypotension & $23(70.0 \%)$ & $9(27.3 \%)$ & $42.7 \%$ (18.4 to 60.2$)$ & 0.001 \\
\hline Bradycardia & $3(9.1 \%)$ & $1(3.0 \%)$ & $6.1 \%(-7.6$ to 20.8$)$ & 0.613 \\
\hline Nausea and vomiting & $9(27.3 \%)$ & $2(6.1 \%)$ & $21.2 \%(3.0$ to 38.7$)$ & 0.044 \\
\hline Time to first use of ephedrine (min) & $4.0[2.0-8.0]$ & $4.0[1.0-10.3]$ & $0.0 \min (-5.9$ to 5.9$)$ & 0.893 \\
\hline Amount of ephedrine required (mg) & $5[0-15]$ & $0[0-5]$ & $5.0 \mathrm{mg}(2.7$ to 7.3$)$ & 0.001 \\
\hline
\end{tabular}

Values shown are median [interquartile range], patient numbers (\%), or the between-group difference with $95 \%$ confidence interval (CI). Group $\mathrm{C}=$ control group; Group $\mathrm{G}=$ glycopyrrolate group
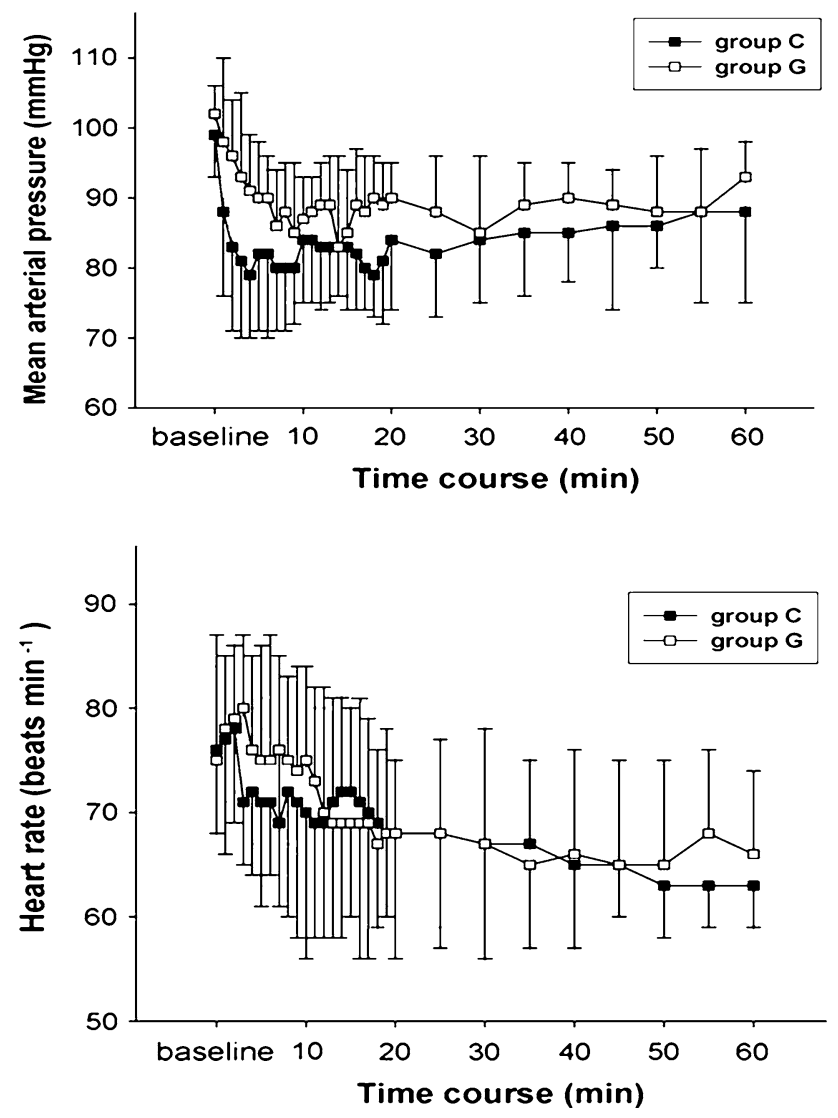

Fig. 2 Mean arterial pressure (MAP) and heart rate (HR) during the study period. The values are presented as median [interquartile range]. Squares represent the median; upper error bars represent the upper quartile in group $\mathrm{G}$; lower error bars represent the lower quartile in group $\mathrm{C}$. Group $\mathrm{C}=$ control group; Group $\mathrm{G}=$ glycopyrrolate group

In conclusion, prophylactic intramuscular glycopyrrolate reduced the occurrence of hypotensive response, the requirement for ephedrine, and the incidence of nausea and vomiting without significant adverse effects in elderly patients during spinal anesthesia.

Declaration of interest The authors report no conflict of interest. We have no financial or other relationships that might lead to conflict of interests regarding this work. We alone are responsible for the content and writing of the paper.

Funding This study was not supported by any funding sources.

\section{References}

1. Hartmann B, Junger A, Klasen J, et al. The incidence and risk factors for hypotension after spinal anesthesia induction: an analysis with automated data collection. Anesth Analg 2002; 94 : 1521-9.

2. Buggy DJ, Power CK, Meeke R, O'Callaghan S, Moran $C$, O'Brien GT. Prevention of spinal anaesthesia-induced hypotension in the elderly: i.m. methoxamine or combined hetastarch and crystalloid. Br J Anaesth 1998; 80: 199-203.

3. Nishikawa K, Yamakage M, Omote K, Namiki A. Prophylactic IM small-dose phenylephrine blunts spinal anesthesia-induced hypotensive response during surgical repair of hip fracture in the elderly. Anesth Analg 2002; 95: 751-6.

4. Meyhoff CS, Haarmark C, Kanters JK, Rasmussen LS. Is it possible to predict hypotension during onset of spinal anesthesia in elderly patients? J Clin Anesth 2009; 21: 23-9.

5. Dobson PM, Caldicott LD, Gerrish SP, Cole JR, Channer KS. Changes in haemodynamic variables during transurethral resection of the prostate: comparison of general and spinal anaesthesia. Br J Anaesth 1994; 72: 267-71.

6. Juelsgaard P, Sand NP, Felsby S, et al. Perioperative myocardial ischaemia in patients undergoing surgery for fractured hip randomized to incremental spinal, single-dose spinal or general anaesthesia. Eur J Anaesthesiol 1998; 15: 656-63.

7. Buggy D, Higgins P, Moran C, O'Brien D, O'Donovan F, McCarroll $M$. Prevention of spinal anesthesia-induced hypotension in the elderly: comparison between preanesthetic administration of crystalloids, colloids, and no prehydration. Anesth Analg 1997; 84: 106-10.

8. Sternlo JE, Rettrup A, Sandin R. Prophylactic i.m. ephedrine in bupivacaine spinal anaesthesia. Br J Anaesth 1995; 74: 517-20.

9. Coe AJ, Revanas B. Is crystalloid preloading useful in spinal anaesthesia in the elderly? Anaesthesia 1990; 45: 241-3.

10. Critchley LA, Stuart JC, Conway F, Short TG. Hypotension during subarachnoid anaesthesia: haemodynamic effects of ephedrine. Br J Anaesth 1995; 74: 373-8.

11. Ali-Melkkila $T$, Kaila $T$, Kanto $J$. Glycopyrrolate: pharmacokinetics and some pharmacodynamic findings. Acta Anaesthesiol Scand 1989; 33: 513-7.

12. Neuman MD, Silber JH, Elkassabany NM, Ludwig JM, Fleisher $L A$. Comparative effectiveness of regional versus general 
anesthesia for hip fracture surgery in adults. Anesthesiology 2012; 117: 72-92.

13. Hollmann $M W$, Wieczorek KS, Smart M, Durieux ME. Epidural anesthesia prevents hypercoagulation in patients undergoing major orthopedic surgery. Reg Anesth Pain Med 2001; 26: 215-22.

14. Rooke GA, Freund PR, Jacobson AF. Hemodynamic response and change in organ blood volume during spinal anesthesia in elderly men with cardiac disease. Anesth Analg 1997; 85: 99-105.

15. Mirakhur RK, Dundee JW. Glycopyrrolate: pharmacology and clinical use. Anaesthesia 1983; 38: 1195-204.

16. Proakis AG, Harris GB. Comparative penetration of glycopyrrolate and atropine across the blood-brain and placental barriers in anesthetized dogs. Anesthesiology 1978; 48: 339-44.

17. Klingenmaier $C H$, Bullard R, Thompson D, Watson R. Reversal of neuromuscular blockade with a mixture of neostigmine and glycopyrrolate. Anesth Analg 1972; 51: 468-72.

18. Cozanitis DA, Dundee JW, Merrett JD, Jones CJ, Mirakhur RK. Evaluation of glycopyrrolate and atropine as adjuncts to reversal of non-depolarizing neuromuscular blocking agents in a "true-tolife" situation. Br J Anaesth 1980; 52: 85-9.

19. Bernstein CA, Waters JH, Torjman MC, Ritter D. Preoperative glycopyrrolate: oral, intramuscular, or intravenous administration. J Clin Anesth 1996; 8: 515-8.

20. Rucklidge $M W$, Durbridge $J$, Barnes PK, Yentis SM. Glycopyrronium and hypotension following combined spinalepidural anaesthesia for elective caesarean section in women with relative bradycardia. Anaesthesia 2002; 57: 4-8.
21. Yentis SM, Jenkins CS, Lucas DN, Barnes PK. The effect of prophylactic glycopyrrolate on maternal haemodynamics following spinal anaesthesia for elective caesarean section. Int $\mathrm{J}$ Obstet Anesth 2000; 9: 156-9.

22. Chamchad D, Horrow JC, Nakhamchik L, et al. Prophylactic glycopyrrolate prevents bradycardia after spinal anesthesia for cesarean section: a randomized, double-blinded, placebocontrolled prospective trial with heart rate variability correlation. J Clin Anesth 2011; 23: 361-6.

23. Ure D, James KS, McNeill M, Booth JV. Glycopyrrolate reduces nausea during spinal anaesthesia for caesarean section without affecting neonatal outcome. Br J Anaesth 1999; 82: 277-9.

24. Fleisher LA, Beckman JA, Brown KA, et al. ACC/AHA 2007 guidelines on perioperative cardiovascular evaluation and care for noncardiac surgery: executive summary: a report of the American College of Cardiology/American Heart Association Task Force on Practice Guidelines (Writing Committee to Revise the 2002 Guidelines on Perioperative Cardiovascular Evaluation for Noncardiac Surgery). Anesth Analg 2008; 106: 685-712.

25. Ali-Melkkila TM, Kaila T, Kanto J, Iisalo E. Pharmacokinetics of i.m. glycopyrronium. Br J Anaesth 1990; 64: 667-9.

26. Ngan Kee WD, Khaw KS, Lau TK, $N g F F$, Chui $K, N g K L$. Randomised double-blinded comparison of phenylephrine vs ephedrine for maintaining blood pressure during spinal anaesthesia for non-elective caesarean section. Anaesthesia 2008; 63: 1319-26. 